\title{
Probabilistic Control Volume Method for Evaluating the Effects of Notch Size and Loading Type on Fatigue Life
}

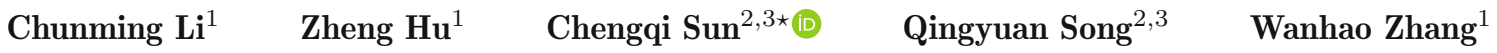 \\ ( ${ }^{1}$ China North Vehicle Research Institute, Beijing 100072, China) \\ $\left({ }^{2}\right.$ State Key Laboratory of Nonlinear Mechanics, Institute of Mechanics, Chinese Academy of Sciences, \\ Beijing 100190, China) \\ $\left({ }^{3}\right.$ School of Engineering Sciences, University of Chinese Academy of Sciences, Beijing 100049, China)
}

Received 7 April 2019; revision received 19 July 2019; Accepted 25 July 2019;

published online 8 August 2019

(C) The Chinese Society of Theoretical and Applied Mechanics 2019

\begin{abstract}
The probabilistic control volume method has great prospects in correlating the effects of specimen size, notch and loading type on fatigue life or fatigue strength. In this work, the effects of notch size and loading type on fatigue life are investigated by using the probabilistic control volume method. Rotating bending and axial loading fatigue tests are at first performed on the hourglass specimen, circumferential V-notch specimen and V-notch plate specimen of 30CrMnSiA steel. Experimental results indicate that the notch reduces the fatigue strength of specimens in terms of nominal stress amplitude while in terms of local stress amplitude, the notch specimen could endure higher fatigue strength. Then, the probabilistic control volume method is used to evaluate the effects of notch size and loading type on fatigue life. It is shown that the probabilistic control volume method correlates well the effects of notch size and loading type on fatigue life, even for the local stress of the notch root exceeding the yield stress of the material.
\end{abstract}

KEY WORDS 30CrMnSiA steel, Notch size, Loading type, Fatigue life, Control volume method

\section{Introduction}

Notches inevitably exist in some components of engineering structures due to the requirement of structural design or during the service, which might greatly decrease the fatigue strength of components due to the stress concentration at the notch root [1-4]. Loading type might also have a significant influence on the fatigue behavior of materials. For example, the specimens under rotating bending fatigue test show higher fatigue strength compared to that under axial loading fatigue test $[5,6]$.

A lot of research has been carried out on the effect of notch or loading type on fatigue behavior [7-10] since the Neuber's method [11] and Peterson's method [12] were proposed for predicting the notch size effect. For example, Kuguel [13] investigated the fatigue strength of notched specimens by introducing a highly stressed volume method, in which the fatigue notch factor $K_{f}$ and the elastic stress concentration factor $K_{t}$ were correlated by the highly stressed volume of the notched specimen $V_{n}$ and that of the smooth specimen $V_{s}$, i.e., $K_{f} / K_{t}=\left(V_{n} / V_{s}\right)^{a}$, where $a$ was a material constant. Taylor [14] used the critical distance method (the area method) to analyze the difference between the fatigue limits in uniaxial tension and in bending for gray cast iron, in which the fatigue damage is assumed to be dominated by the average stress over a certain volume in the vicinity of the stress concentrator

\footnotetext{
* Corresponding author. E-mail: scq@lnm.imech.ac.cn
} 
(i.e., effective stress), and the fatigue failure of notched components occurs when the effective stress exceeds the plain fatigue limit of the material [14, 15]. Wang and Yang [16] investigated the highcycle fatigue strength of notched $\mathrm{Ti}-6 \mathrm{Al}-4 \mathrm{~V}$ alloy specimens by assuming constant product of critical distance and elastic stress concentration factor to overcome the critical distance size effect. Naik et al. [17] developed a critical plane gradient approach for predicting high-cycle fatigue life of notched Ti$6 \mathrm{Al}-4 \mathrm{~V}$ alloy by the critical plane damage parameter and the stress gradient at the notch. Gallo et al. [18] used the strain energy density averaged over a control volume to assess the fatigue data of notched specimens of titanium grade 2 under high-temperature fatigue test. Based upon the assumption that the large specimen could be seen composed of a number of small specimens via the control volume, Sun et al. [19, 20] developed a probabilistic control volume method for evaluating the effects of specimen geometry and loading condition on fatigue life and fatigue strength from the view of statistical analysis, i.e., $\left(N_{A}-\gamma\right) /\left(N_{B}-\gamma\right)=\left(V_{A} / V_{B}\right)^{-1 / k}$ and $\left(\sigma_{A}-\gamma^{\prime}\right) /\left(\sigma_{B}-\gamma^{\prime}\right)=\left(V_{A} / V_{B}\right)^{-1 / k^{\prime}}$, where $N_{A}$ and $N_{B}$ denote the fatigue lives in the logarithmic scale; $\sigma_{A}$ and $\sigma_{B}$ denote the fatigue strengths; $V_{A}$ and $V_{B}$ denote the control volumes; subscripts $\mathrm{A}$ and $\mathrm{B}$ denote the quantities for specimens $\mathrm{A}$ and $\mathrm{B}$, respectively; $\gamma$ and $k$ denote the location parameter and shape parameter of Weibull distribution for the fatigue life in the logarithmic scale, respectively; and $\gamma^{\prime}$ and $k^{\prime}$ denote the location parameter and shape parameter of Weibull distribution for the fatigue strength, respectively. It showed good agreement for high-strength steels, titanium alloy $\mathrm{Ti}-6 \mathrm{Al}-2 \mathrm{Sn}-2 \mathrm{Zr}-3 \mathrm{Mo}-\mathrm{X}$ and full-scale EA4T axles.

In this work, rotating bending and axial loading fatigue tests are performed on the specimens of $30 \mathrm{CrMnSiA}$ steel often used for wheel shafts and wheel gears and subjected to fatigue loadings in service, and the effects of notch size and loading type on fatigue life are investigated by using the probabilistic control volume method.

\section{Materials and Methods}

The specimens used are cut from plates of 30CrMnSiA steel, the average tensile strength and yield strength of which are $670 \mathrm{MPa}$ and $405 \mathrm{MPa}$, respectively. The tensile test is conducted on three cylindrical specimens with the diameter of $5 \mathrm{~mm}$ by the Landmark servohydraulic test system, as shown in Fig. 1.

Three kinds of specimens are used, which are the hourglass specimen, circumferential V-notch specimen and V-notch plate specimen, as shown in Fig. 2. All the test sections are ground and polished to eliminate machine scratches before the fatigue tests. The value of the elastic stress concentration factor $K_{t}$ is calculated using the Abaqus 6.14 software, which is defined as the ratio of the maximum principal stress at the notch root to that of the smallest cross section area in smooth specimen (i.e., nominal stress), and is listed in Table 1. Young's modulus is $196 \mathrm{GPa}$, and Poisson's ratio is 0.3.

The rotating bending fatigue test is conducted with a rotating bending machine YRB200 at a frequency of $50 \mathrm{~Hz}$, and the axial loading fatigue test is conducted on a servohydraulic test system at a frequency of $10 \mathrm{~Hz}$. Both fatigue tests are conducted at room temperature, and the stress ratio $R$ is -1 . The fracture surfaces of all failed specimens are observed by a JSM-IT300 scanning electron microscope (SEM).

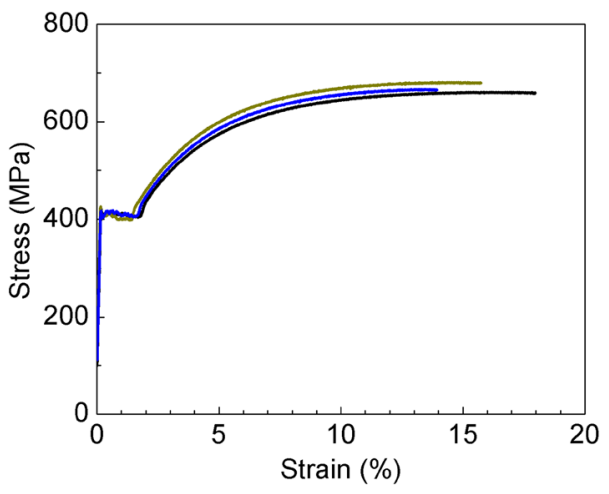

Fig. 1. Relation of stress and strain of three specimens under tensile test 
(a)

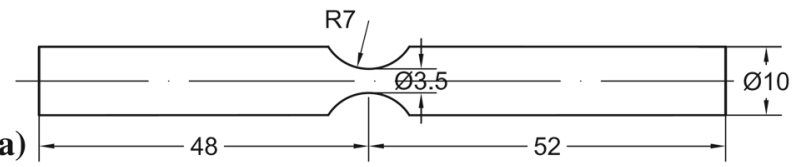

(b)

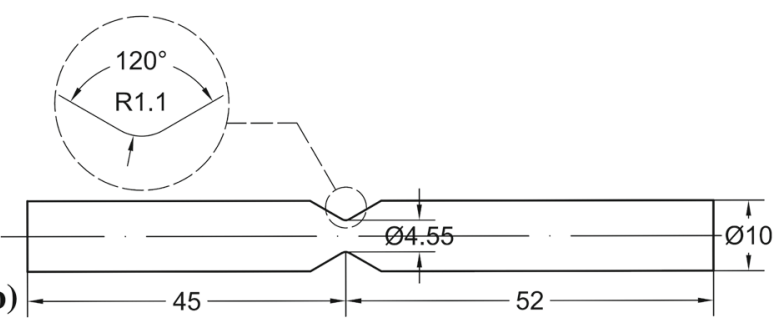

(c)

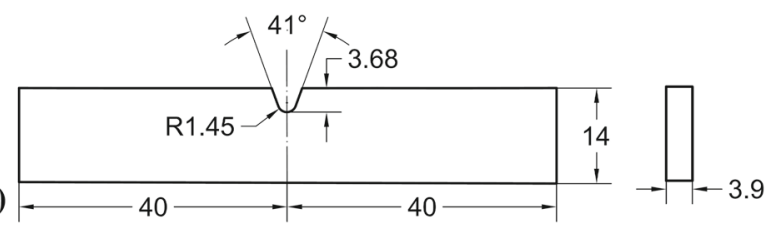

Fig. 2. Shape and dimensions (in $\mathrm{mm}$ ) of specimens for the fatigue tests: a hourglass specimen under rotating bending fatigue test (hourglass specimen-RB); b circumferential V-notch specimen under rotating bending fatigue test (notch specimen-RB); c V-notch plate specimen under axial loading fatigue test (notch specimen-AL)

Table 1. Elastic stress concentration factor $K_{t}$ of specimens

\begin{tabular}{llll}
\hline & Hourglass specimen-RB & Notch specimen-RB & Notch specimen-AL \\
\hline$K_{t}$ & 1.07 & 1.52 & 4.69 \\
\hline
\end{tabular}

\subsection{S-N Data}

\section{Experimental Results and Analyses}

Figure 3 shows the S-N data of the hourglass specimen, circumferential V-notch specimen and Vnotch plate specimen under rotating bending and axial loading fatigue tests. It is seen from Fig. 3 that the notch has a significant influence on the fatigue strength or fatigue life of the tested material. In terms of nominal stress amplitude in Fig. 3a, the notch specimen shows lower fatigue strength due to the higher stress concentration induced by the notch root in comparison with the hourglass specimen under rotating bending fatigue test, and the fatigue strength decreases with the increase in elastic stress concentration factor while in terms of local stress amplitude in Fig. 3b, the notch specimen endures higher fatigue strength than that of the hourglass specimen at the same fatigue life, and the fatigue strength tends to increase with the increase in elastic stress concentration factor.

The local stress in Fig. 3b is calculated using the Abaqus 6.14 software. For the stress higher than the yield stress, the multi-linear relation of stress and plastic strain in Fig. 4 is applied in the calculation according to the average value of the stress-strain curve in Fig. 1. The original experimental data of the specimens by the nominal stress amplitude associated with the fatigue life are given in Table 2.

\subsection{SEM Observation of Fracture Surface}

The SEM observation shows that all the hourglass specimens and notch specimens fail from the specimen surface. Figures 5, 6, 7 show the typical morphology of the fracture surface for the three kinds of specimens, respectively. For hourglass specimens, only single-site crack initiation is observed. For notch specimen-RB, only one specimen fails from single-site crack initiation, and others fail from multi-site crack initiation. For notch specimen-AL, most specimens fail from single-site crack initiation and few fail from multi-site crack initiation, although the elastic stress concentration factor of the notch specimen-AL is larger than that of the notch specimen-RB. This indicates that the crack initiation mode is related to both the specimen geometry and the loading type. The SEM observation also 

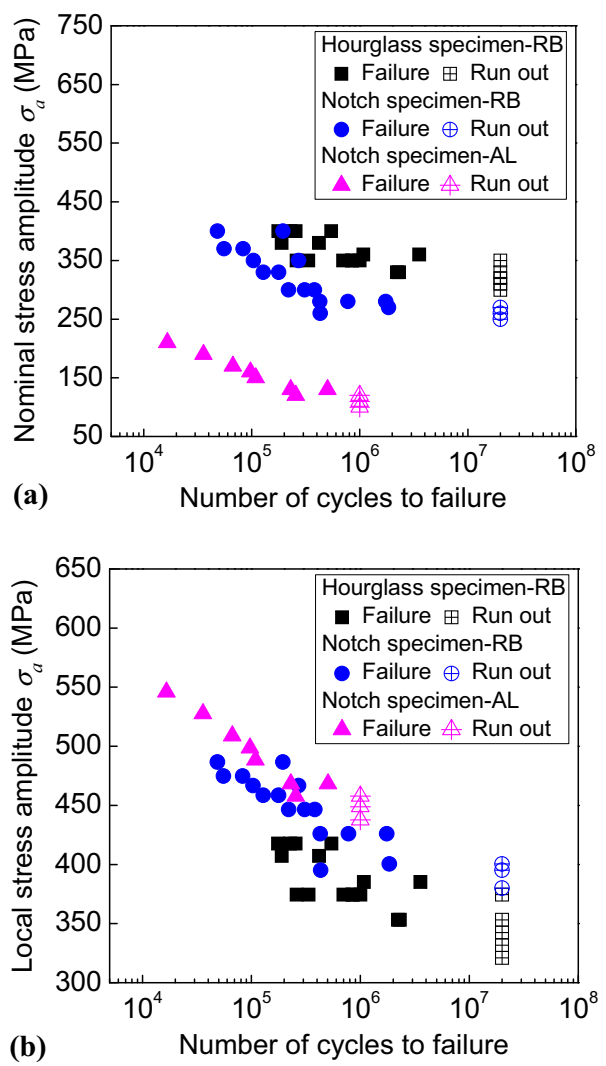

Fig. 3. S-N data of hourglass specimen-RB, notch specimen-RB and notch specimen-AL, in which "run out" denotes the specimen unbroken: a nominal stress amplitude versus fatigue life; $\mathbf{b}$ local stress amplitude versus fatigue life

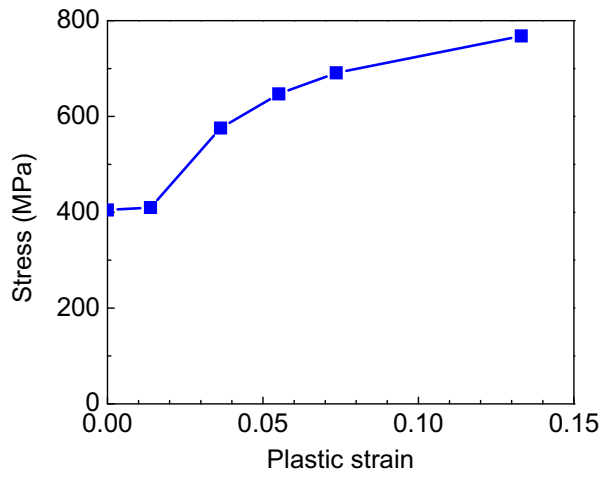

Fig. 4. Relation of stress and plastic strain inputted for the calculation of stress-strain analysis of the tested specimens

indicates that the crack origins of the $30 \mathrm{CrMnSiA}$ steel have different forms, which could initiate from grains, inclusions or holes.

\section{Effects of Notch Size and Loading Type on Fatigue Life}

According to the work by Sun et al. [19], if specimens A and B could be seen composed of a number of referring specimens with very small control volumes, and the fatigue life in the logarithmic scale follows the two-parameter Weibull distribution, the fatigue life of specimen A and that of specimen B could be correlated as

$$
\frac{N_{A}}{N_{B}}=\left(\frac{V_{A}}{V_{B}}\right)^{-\frac{1}{k}}
$$


Table 2. Original experimental data of specimens shown in Fig 3a

\begin{tabular}{|c|c|c|c|c|c|}
\hline \multicolumn{2}{|c|}{ Hourglass specimen-RB } & \multicolumn{2}{|c|}{ Notch specimen-RB } & \multicolumn{2}{|c|}{ Notch specimen-AL } \\
\hline$\sigma_{a}(\mathrm{MPa})$ & $N_{f}$ & $\sigma_{a}(\mathrm{MPa})$ & $N_{f}$ & $\sigma_{a}(\mathrm{MPa})$ & $N_{f}$ \\
\hline 400 & $5.44 \times 10^{5}$ & 400 & $4.83 \times 10^{4}$ & 210 & $1.66 \times 10^{4}$ \\
\hline 400 & $2.54 \times 10^{5}$ & 400 & $1.94 \times 10^{5}$ & 190 & $3.58 \times 10^{4}$ \\
\hline 400 & $2.27 \times 10^{5}$ & 370 & $5.54 \times 10^{4}$ & 170 & $6.68 \times 10^{4}$ \\
\hline 400 & $1.76 \times 10^{5}$ & 370 & $8.32 \times 10^{4}$ & 160 & $9.70 \times 10^{4}$ \\
\hline 380 & $4.18 \times 10^{5}$ & 350 & $1.04 \times 10^{5}$ & 150 & $1.09 \times 10^{5}$ \\
\hline 380 & $1.90 \times 10^{5}$ & 350 & $2.72 \times 10^{5}$ & 130 & $2.30 \times 10^{5}$ \\
\hline 360 & $3.55 \times 10^{6}$ & 330 & $1.28 \times 10^{5}$ & 130 & $5.03 \times 10^{5}$ \\
\hline 360 & $1.08 \times 10^{6}$ & 330 & $1.78 \times 10^{5}$ & 120 & $2.56 \times 10^{5}$ \\
\hline 350 & $9.98 \times 10^{5}$ & 300 & $2.19 \times 10^{5}$ & 120 & $1.0 \times 10^{6 *}$ \\
\hline 350 & $8.52 \times 10^{5}$ & 300 & $3.81 \times 10^{5}$ & 110 & $1.0 \times 10^{6 *}$ \\
\hline 350 & $8.46 \times 10^{5}$ & 300 & $3.08 \times 10^{5}$ & 100 & $1.0 \times 10^{6 *}$ \\
\hline 350 & $7.02 \times 10^{5}$ & 280 & $1.75 \times 10^{6}$ & & \\
\hline 350 & $3.34 \times 10^{5}$ & 280 & $7.77 \times 10^{5}$ & & \\
\hline 350 & $2.61 \times 10^{5}$ & 280 & $4.27 \times 10^{5}$ & & \\
\hline 330 & $2.31 \times 10^{6}$ & 270 & $1.85 \times 10^{6}$ & & \\
\hline 330 & $2.21 \times 10^{6}$ & 260 & $4.31 \times 10^{5}$ & & \\
\hline 350 & $2.0 \times 10^{7 *}$ & 270 & $2.0 \times 10^{7 *}$ & & \\
\hline 330 & $2.0 \times 10^{7 *}$ & 260 & $2.0 \times 10^{7 *}$ & & \\
\hline 320 & $2.0 \times 10^{7 *}$ & 260 & $2.0 \times 10^{7 *}$ & & \\
\hline 310 & $2.0 \times 10^{7 *}$ & 250 & $2.0 \times 10^{7 *}$ & & \\
\hline 300 & $2.0 \times 10^{7 *}$ & & & & \\
\hline
\end{tabular}

*It denotes the specimen unbroken

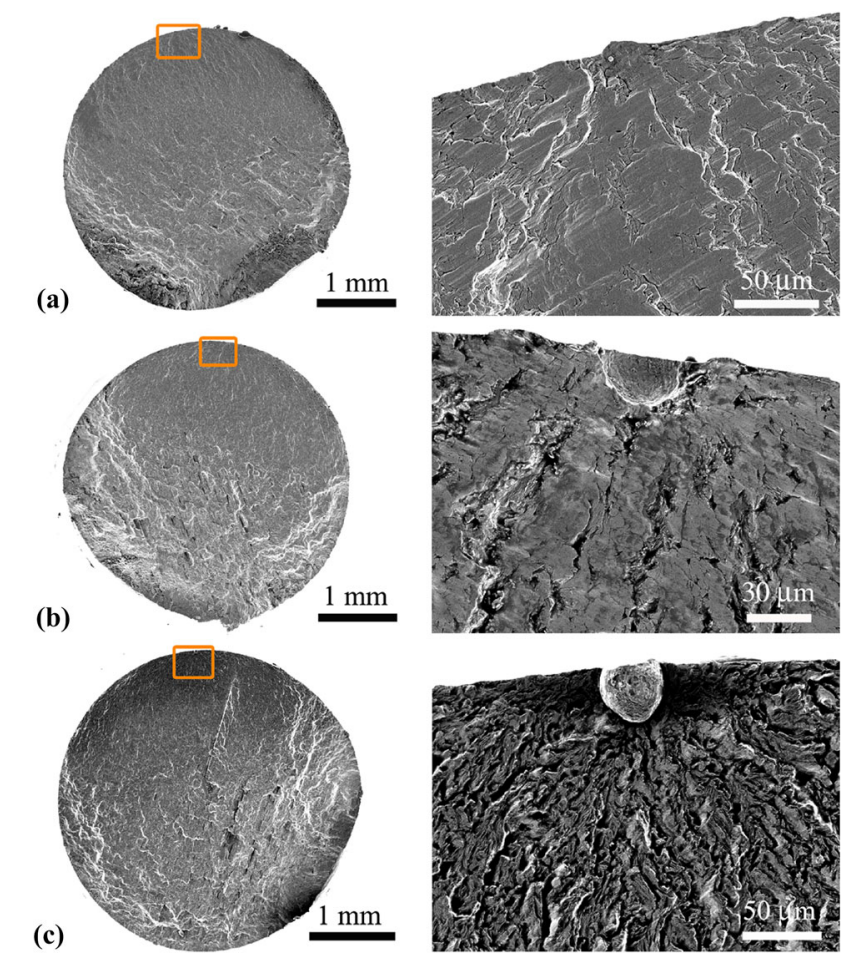

Fig. 5. SEM images of fracture surface for hourglass specimen-RB: a single-site crack initiation from the grain at nominal stress amplitude $\sigma_{a}=360 \mathrm{MPa}$ and $N_{f}=3.55 \times 10^{6} ; \mathbf{b}$ single-site crack initiation from the hole at nominal stress amplitude $\sigma_{a}=350 \mathrm{MPa}$ and $N_{f}=8.52 \times 10^{5}$; c single-site crack initiation from the inclusion at nominal stress amplitude $\sigma_{a}=350 \mathrm{MPa}$ and $N_{f}=3.34 \times 10^{5}$ 


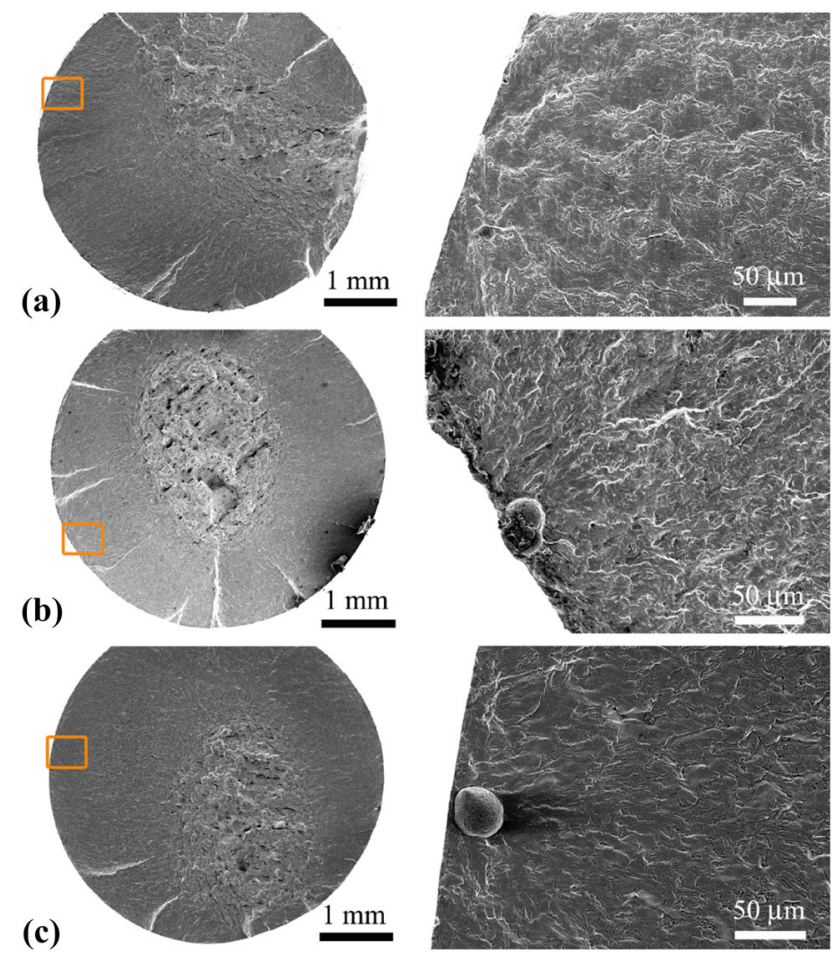

Fig. 6. SEM images of fracture surface for notch specimen-RB with multi-site crack initiation: a nominal stress amplitude $\sigma_{a}=330 \mathrm{MPa}$ and $N_{f}=1.78 \times 10^{5} ; \mathbf{b}$ nominal stress amplitude $\sigma_{a}=370 \mathrm{MPa}$ and $N_{f}=8.32 \times 10^{4} ; \mathbf{c}$ nominal stress amplitude $\sigma_{a}=300 \mathrm{MPa}$ and $N_{f}=3.08 \times 10^{5}$
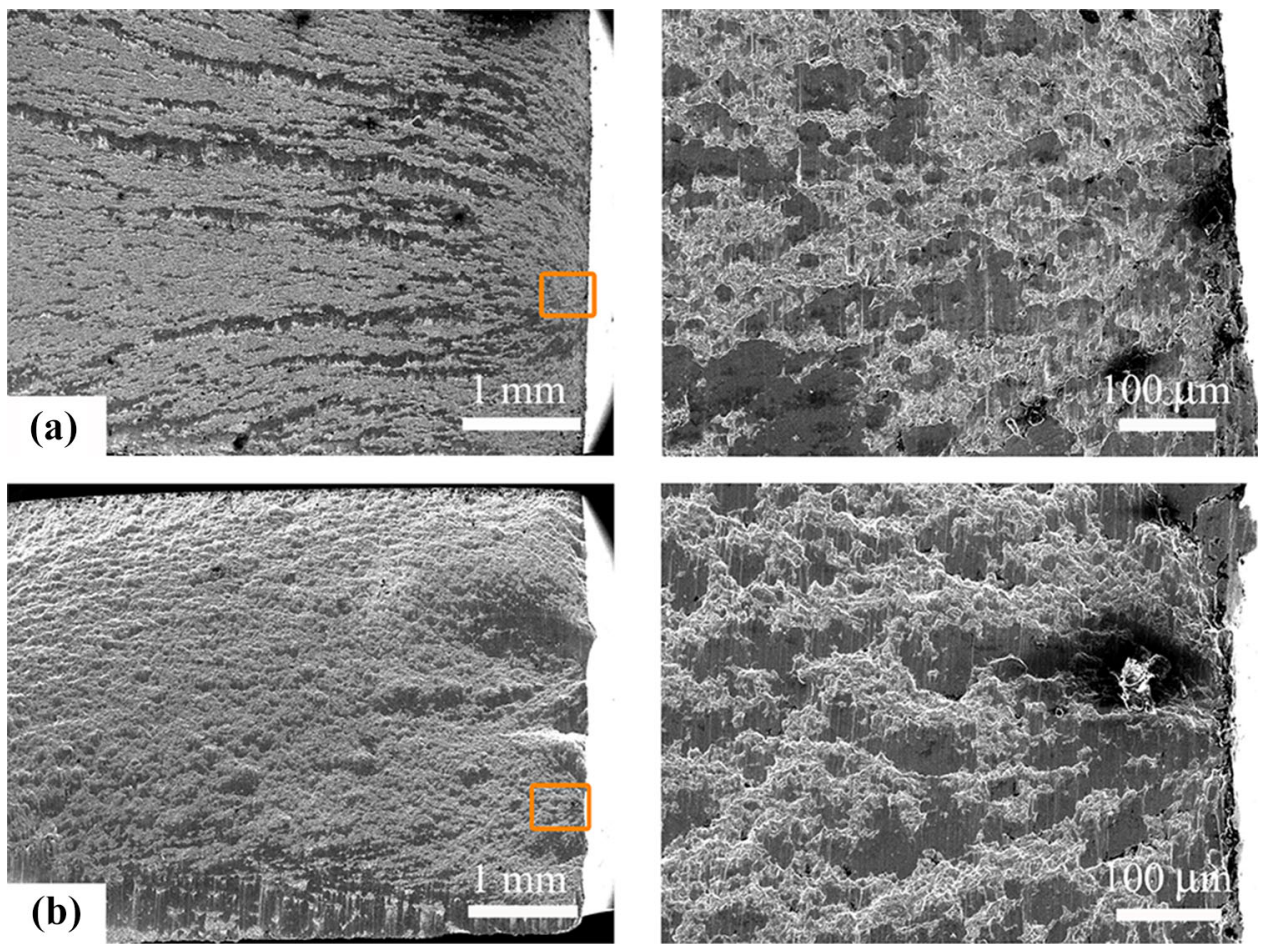

Fig. 7. SEM images of fracture surface for notch specimen-AL: a single-site crack initiation from the grain at nominal stress amplitude $\sigma_{a}=130 \mathrm{MPa}$ and $N_{f}=5.03 \times 10^{5} ; \mathbf{b}$ multi-site crack initiation from the grain at nominal stress amplitude $\sigma_{a}=210 \mathrm{MPa}$ and $N_{f}=1.66 \times 10^{4}$ 


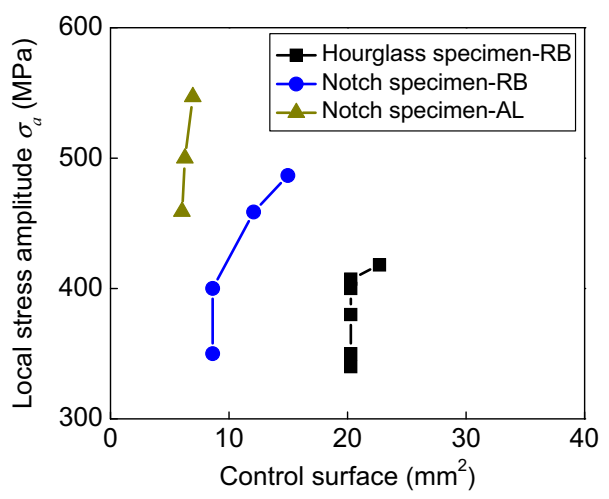

Fig. 8. Local stress amplitude versus control surface for the three kinds of specimens

where $N_{A}$ is the fatigue life in the logarithmic scale for specimen A; $N_{B}$ is the fatigue life in the logarithmic scale for specimen $\mathrm{B} ; V_{A}$ and $V_{B}$ are control volumes for specimens $\mathrm{A}$ and $\mathrm{B}$, respectively; and $k>0$ is the shape parameter of the two-parameter Weibull distribution of fatigue life in the logarithmic scale.

For the crack initiating from the surface, the control surface with a certain thickness (e.g., the magnitude of several grains) should be more appropriate, i.e.,

$$
\frac{N_{A}}{N_{B}}=\left(\frac{S_{A}}{S_{B}}\right)^{-\frac{1}{k}}
$$

where $S_{A}$ and $S_{B}$ denote the control surfaces of specimens A and B, respectively.

The control volume or the control surface is usually taken as the region no less than $90 \%$ of the maximum principal stress of the specimen [5, 19-21].

Considering that all the hourglass and notched specimens of the tested material fail from the surface of the specimen, Eq. (2) is used for correlating the effects of notch size and loading type on the fatigue life, and the procedure of P-S-N curve prediction by Sun et al. [21] is used to transform the fatigue life under different stress levels to that under an arbitrary given stress level for hourglass specimen-RB, and then, the parameter $k$ and the fatigue life at some certain survival probabilities are obtained. For hourglass specimen, the control surface is taken as the surface region of the specimen subjected to no less than $90 \%$ of the maximum principle stress on the specimen surface. For circumferential V-notch specimen and V-notch plate specimen, the control surface is taken as the surface region of the notch root subjected to no less than $90 \%$ of the maximum principle stress on the surface of the notch root. The control surface is calculated using the Abaqus 6.14 software. It is noted that when the maximum principle stress exceeds the yield stress of the material, the control surface is related to the maximum principle stress (stress amplitude) and increases with the increase in the maximum principle stress, as shown in Fig. 8.

Figure 9 shows the comparison between the predicted P-S-N curves with the experimental data for hourglass specimen-RB, in which the fatigue life data of hourglass specimen-RB with the control surface of $20.28 \mathrm{~mm}^{2}$ are used for determining the parameters of Weibull distribution of fatigue life in the logarithmic scale. It is seen that the predicted $50 \%$-survival-probability curve is generally in the middle of the scattered experimental data, and most of the experimental data are within the predicted 90\%- and 10\%-survival-probability curves, indicating that the predicted P-S-N curves accord with the experimental data.

Now, the experimental data of the hourglass specimen-RB with the control surface of $20.28 \mathrm{~mm}^{2}$ are used to predict the P-S-N curves of notch specimen-RB and notch specimen-AL by using Eq. (2), and the results are shown in Fig. 10. It is seen that, for both the notch specimen-RB and the notch specimen-AL, the predicted P-S-N curves are in agreement with the experimental data. This indicates that the probabilistic control volume method is capable of predicting the effects of both the notch size 


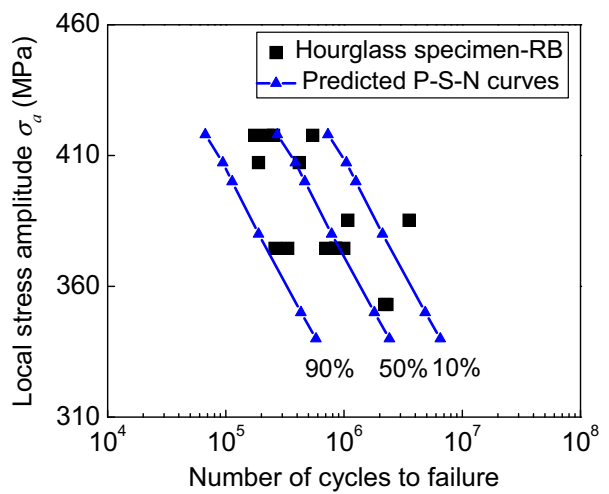

Fig. 9. Comparison between the predicted P-S-N curves with the experimental data for hourglass specimen-RB

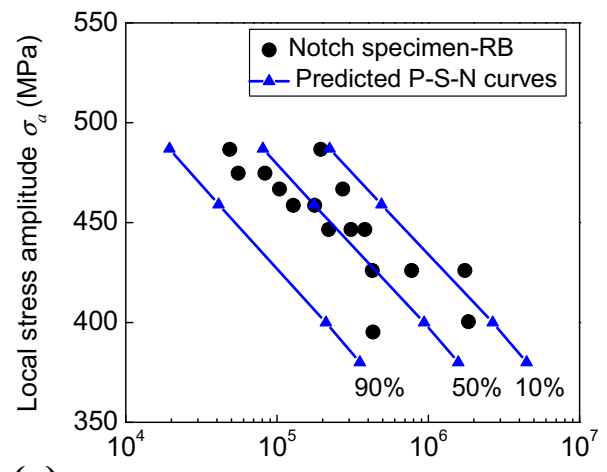

(a)

Number of cycles to failure

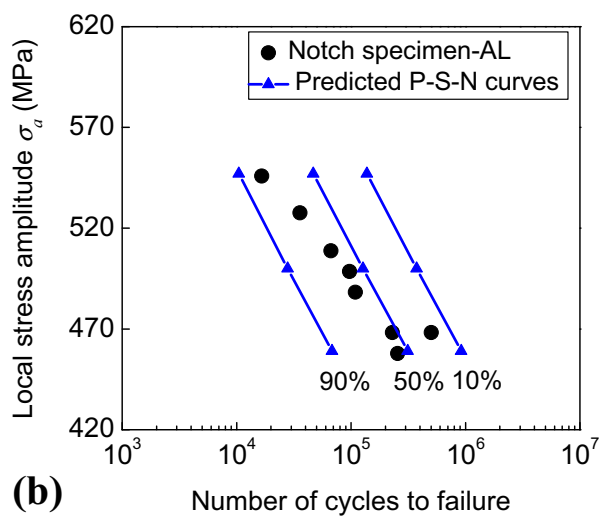

Fig. 10. Comparison between the predicted $\mathrm{P}-\mathrm{S}-\mathrm{N}$ curves with the experimental results using the fatigue life data from hourglass specimen-RB: a for notch specimen-RB; $\mathbf{b}$ for notch specimen-AL

and the loading type on the fatigue life of $30 \mathrm{CrMnSiA}$ steel, even for the local maximum principle stress in the highly stressed region exceeding the yield stress of the material.

\section{Conclusions}

In this work, the effects of notch size and loading type on fatigue life are investigated by using the probabilistic control volume method based on the experimental data for hourglass specimen and notched specimens of $30 \mathrm{CrMnSiA}$ steel under rotating bending and axial loading fatigue tests. The experimental data indicate that the notch reduces the fatigue strength of the specimen in terms of nominal stress amplitude, and the fatigue strength decreases with the increase in elastic stress concentration factor. While in terms of local stress amplitude, the notch specimen could endure higher fatigue 
strength, and the fatigue strength tends to increase with the increase in elastic stress concentration factor. It is shown that the effects of notch size and loading type on the fatigue life of $30 \mathrm{CrMnSiA}$ steel could be evaluated by the probabilistic control volume method, i.e., $N_{A} / N_{B}=\left(S_{A} / S_{B}\right)^{-1 / k}$, where $N_{A}$ and $N_{B}$ denote the fatigue lives in the logarithmic scale for specimen $\mathrm{A}$ and specimen B, respectively; $S_{A}$ and $S_{B}$ denote the control surfaces for specimen A and specimen B, respectively; and $k$ denotes the shape parameter of the two-parameter Weibull distribution for the fatigue life in the logarithmic scale.

Acknowledgements. The authors would like to acknowledge the support from the Innovation Program (237099000000170004), the National Natural Science Foundation of China (91860112) and the Strategic Priority Research Program of the Chinese Academy of Sciences (XDB22020200).

\section{References}

[1] Akiniwa Y, Miyamoto N, Tsuru H, Tanaka K. Notch effect on fatigue strength reduction of bearing steel in the very high cycle regime. Int J Fatigue. 2006;28:1555-65.

[2] Hertel O, Vormwald M. Statistical and geometrical size effects in notched members based on weakest-link and short-crack modelling. Eng Fract Mech. 2012;95:72-83.

[3] Wang R, Li D, Hu D, Meng F, Liu H, Ma Q. A combined critical distance and highly-stressed-volume model to evaluate the statistical size effect of the stress concentrator on low cycle fatigue of TA19 plate. Int J Fatigue. 2017;95:8-17.

[4] Leitner M, Vormwald M, Remes H. Statistical size effect on multiaxial fatigue strength of notched steel components. Int J Fatigue. 2017;104:322-33.

[5] Murakami Y, Yokoyama NN, Nagata J. Mechanism of fatigue failure in ultralong life regime. Fatigue Fract Eng Mater Struct. 2002;25:735-46.

[6] Nakajima M, Tokaji K, Itoga H, Shimizu T. Effect of loading condition on very high cycle fatigue behavior in a high strength steel. Int J Fatigue. 2010;32:475-80.

[7] Haritos GK, Nicholas T, Lanning DB. Notch size effects in HCF behavior of Ti-6Al-4V. Int J Fatigue. $1999 ; 21: 643-52$.

[8] Lei Z, Xie J, Sun C, Hong Y. Effect of loading condition on very-high-cycle fatigue behavior and dominant variable analysis. Sci China Phys Mech Astron. 2014;57:74-82.

[9] Owolabi G, Okeyoyin O, Bamiduro O, Olasumboye A, Whitworth H. The effects of notch size and material microstructure on the notch sensitivity factor for notched components. Eng Fract Mech. 2015;145:181-96.

[10] Hu Y, Sun C, Xie J, Hong Y. Effects of loading frequency and loading type on high-cycle and very-highcycle fatigue of a high-strength steel. Materials. 2018;11:1456.

[11] Neuber H. Theory of notch stresses: principles for exact calculation of strength with reference to structural form and material. 2nd ed. Berlin: Springer; 1958.

[12] Peterson RE. Notch sensitivity. In: Sines G, Waisman JL, editors. Metal fatigue. New York: McGraw Hill; 1959. p. 293-306.

[13] Kuguel RA. A relation between theoretical stress concentration factor and fatigue notch factor deduced from the concept of highly stressed volume. ASTM Proc. 1961;61:732-48.

[14] Taylor D. Geometrical effects in fatigue: a unifying theoretical model. Int J Fatigue. 1999;21:413-20.

[15] Susmel L. The theory of critical distances: a review of its applications in fatigue. Eng Fract Mech. 2008; $75: 1706-24$.

[16] Wang J, Yang X. HCF strength estimation of notched Ti-6Al-4V specimens considering the critical distance size effect. Int J Fatigue. 2012;40:97-104.

[17] Naik RA, Lanning DB, Nicholas T, Kallmeyer AR. A critical plane gradient approach for the prediction of notched HCF life. Int J Fatigue. 2005;27:481-92.

[18] Gallo P, Berto F, Lazzarin P. High temperature fatigue tests of notched specimens made of titanium Grade 2. Theor Appl Fract Mech. 2015;76:27-34.

[19] Sun C, Song Q. A method for evaluating the effects of specimen geometry and loading condition on fatigue life of metallic materials. Mater Res Express. 2019;6:046536.

[20] Sun C, Song Q. A method for predicting the effects of specimen geometry and loading condition on fatigue strength. Metals. 2018;8:811.

[21] Sun C, Zhang X, Liu X, Hong Y. Effects of specimen size on fatigue life of metallic materials in high-cycle and very-high-cycle fatigue regimes. Fatigue Fract Eng Mater Struct. 2016;39:770-9. 